Research Article

\title{
Synthesis of Two Novel Homologous Polyphosphoesters Containing Aminophosphonate Units and Cytotoxicity of Some Low-Molecular and Polymeric Aminophosphonate Derivatives
}

\author{
Ivanka Kraicheva (D), ${ }^{1}$ Georgi Momekov ${ }^{D},{ }^{2}$ Rositsa Mihaylova, \\ Margarita Topashka-Ancheva, ${ }^{3}$ Ivelina Tsacheva, ${ }^{1}$ Ivanka Stoineva, ${ }^{4}$ \\ Elitsa Vodenicharova, ${ }^{1}$ and Paraskev Nedialkov ${ }^{5}$ \\ ${ }^{1}$ Institute of Polymers, Bulgarian Academy of Sciences, Sofia 1113, Bulgaria \\ ${ }^{2}$ Department of Pharmacology, Pharmacotherapy and Toxicology, Faculty of Pharmacy, Medical University-Sofia, \\ Sofia 1000, Bulgaria \\ ${ }^{3}$ Institute of Biodiversity and Ecosystems Research, Bulgarian Academy of Sciences, Sofia 1113, Bulgaria \\ ${ }^{4}$ Institute of Organic Chemistry with Centre of Phytochemistry, Bulgarian Academy of Sciences, Sofia 1113, Bulgaria \\ ${ }^{5}$ Department of Pharmacognosy, Faculty of Pharmacy, Medical University-Sofia, Sofia 1000, Bulgaria
}

Correspondence should be addressed to Ivanka Kraicheva; igkraicheva@gmail.com

Received 28 March 2018; Revised 18 June 2018; Accepted 24 June 2018; Published 13 August 2018

Academic Editor: Claudio Pettinari

Copyright (c) 2018 Ivanka Kraicheva et al. This is an open access article distributed under the Creative Commons Attribution License, which permits unrestricted use, distribution, and reproduction in any medium, provided the original work is properly cited.

\begin{abstract}
Two novel polyphosphoesters containing anthracene- and furan-derived aminophosphonate moieties, namely, poly[oxyethylene (aminophosphonate-co-H-phosphonate)]s P-12 and P-13, were synthesized through an addition of poly(oxyethylene H-phosphonate) to 9-anthrylidene-furfurylamine and characterized. The novel polyphosphoester $\mathbf{P}-\mathbf{1 2}$ and a series of previously described anthracene-derived compounds including Schiff bases S-1 and S-2, $\alpha$-aminophosphonates A-3-A-6, bis-aminophosphonate B-6, two enantiomers A-5a and $\mathbf{A}-\mathbf{5 b}$, and polyphosphoesters P-8-P-11 containing aminophosphonate units were screened for antitumor activity against a panel of human leukemic cell lines, using cisplatin as a reference cytotoxic agent. As concluded from the cytotoxicity assays, both precursors S-1 and S-2 presented similar cytotoxicity profiles that are cisplatin-like only in the REH cell line. Leader compound of the $\alpha$-aminophosphonates is A-4 with cell death-inducing properties fully equaling those of the referent drug in all of the screened leukemic cell lines with the only exception being the AML histological subtype HL-60. Some of the polymeric analogues elicited moderate (P-10 and P-12) to low (P-11) cytotoxic activity, whereas the polyphosphoesters $\mathbf{P}-\mathbf{8}$ and $\mathbf{P}-\mathbf{9}$ produced in vitro antitumor effects largely surpassing cisplatin's. The compounds $\mathbf{P}-\mathbf{8}, \mathbf{P}-\mathbf{9}$, and A-4 could be potential new materials for anticancer therapeutic purposed.
\end{abstract}

\section{Introduction}

The aminophosphonic acid derivatives are an interesting class of biologically active compounds, which possess diverse and useful properties, including herbicidal, antibacterial, antiviral, and antitumor activity [1-3]. They have found important applications, especially in the field of medicine and agriculture $[1,4,5]$. Thus, bisphosphonates are widely used in the treatment of cancer-induced bone diseases [6, 7]. They inhibit osteoclastic bone resorption and delay the further progression of bone metastases $[7,8]$. The in vitro studies have revealed that the nitrogen-containing bisphosphonates (zoledronic acid, pamidronate, and incadronate) exert direct cytostatic and proapoptotic effects on human tumor cell lines, as myeloma, breast, prostate, and pancreas cancer cell lines $[7,8]$. Radiolabelled complexes of aminophosphonate derivatives are used for diagnosis and treatment of tumors in humans and animals $[4,9,10]$. A number of novel aminophosphonate derivatives bearing heterocycles [11-15], dehydroabietic acid moiety [16], diacerein conjugates [17], and bis- $\mathrm{CF}_{3}$ group [18] 
have been synthesized and evaluated for antitumor activity against different human cancer cell lines [11-18]. According to the data reported, many of these compounds show quite promising cytotoxic activity against the corresponding human cancer cell lines used in the biological assays $[11,12,14-18]$.

The immobilization of aminophosphonate moieties to biodegradable polymer carriers is an effective way for the formation of new type of polymer prodrugs with improved properties $[19,20]$. The polymer-drug conjugates seem to hold great potential to circumvent major disadvantages of the conventional drug therapy $[21,22]$.

Polyphosphoesters comprise a class of biodegradable and biocompatible phosphorus-containing polymers [23]. They degrade into nontoxic products through hydrolysis and enzymatic cleavage of their phosphoester bonds under physiological conditions [22, 24]. The poly(alkylene $\mathrm{H}$-phosphonate)s contain reactive $\mathrm{P}-\mathrm{H}$ groups, which allow for the chemical attachment of drug molecules to the polymer chain $[22,23]$.

In the present study, we report on the synthesis and spectroscopic characterization of two novel homologous polyphosphoesters containing anthracene- and furanderived aminophosphonate units. One of them was evaluated for cytotoxicity against a panel of human leukemic cell lines, including HL-60, SKW-3, REH, and K-562 cells.

Low-molecular and polymeric aminophosphonates, synthesized earlier [20,25-28], were also studied against the same tumor cell lines.

\section{Results and Discussion}

2.1. Chemistry. Novel homologous polyphosphoesters, namely, poly[oxyethylene (aminophosphonate-co-Hphosphonate)]s P-12 and P-13 (Scheme 1), which contain anthracene- and furan-derived aminophosphonate units, have been synthesized through an addition of poly(oxyethylene $\mathrm{H}$-phosphonate) $\mathbf{1}$ to the Schiff base 9-anthrylidenefurfurylamine S-2. The polymer analogous reaction was carried out using an excess of the Schiff base and in the presence of $\mathrm{CdI}_{2}$ as a catalyst. The polymer $\mathbf{P}-\mathbf{1 2}$ was obtained in a good yield (69\%) by conventional heating of the reagents at $60^{\circ} \mathrm{C}$ for $25 \mathrm{~h}$. The preparation of the polymer $\mathbf{P}-\mathbf{1 3}$ was accomplished for a shorter reaction time $(1 \mathrm{~h})$ and in a higher yield $(88 \%)$ with the assistance of microwave irradiation. The products $\mathbf{P}-\mathbf{1 2}$ and $\mathbf{P}-\mathbf{1 3}$ were obtained as viscous oils, soluble in common organic solvents (toluene, chloroform, methanol, and ethanol) and in water.

The structure of the polyphosphoesters $\mathbf{P}-\mathbf{1 2}$ and $\mathbf{P}-\mathbf{1 3}$ was verified by means of IR and NMR spectral analysis. The IR spectra displayed absorption bands characteristic for stretching vibration of $\mathrm{NH}, \mathrm{PH}, \mathrm{P}=\mathrm{O}$, and $\mathrm{P}-\mathrm{O}-\mathrm{C}$ groups. ${ }^{1} \mathrm{H}$ NMR spectra of the products showed doublet signals at 5.68 and $5.71 \mathrm{ppm}\left(\mathbf{P}-\mathbf{1 2}\right.$, in $\mathrm{CDCl}_{3}$ and in $\mathrm{DMSO}_{-} \mathrm{d}_{6}$, respectively) and $5.69 \mathrm{ppm}\left(\mathbf{P}-13\right.$, in $\left.\mathrm{CDCl}_{3}\right)$ with ${ }^{2} J_{\mathrm{PH}}$ about $23 \mathrm{~Hz}$ which can be assigned to the CHP proton from their units formed by addition reaction between the polymeric $\mathrm{H}$-phosphonate and the Schiff base. The NH proton signal is masked in the spectra taken in $\mathrm{CDCl}_{3}$ solution. In the
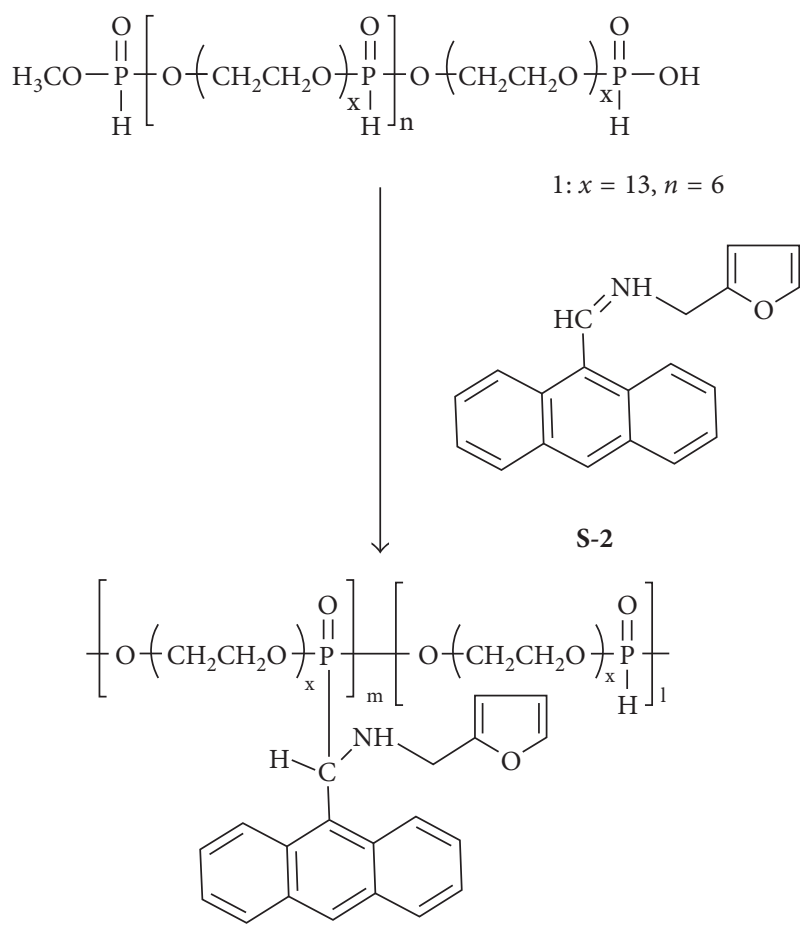

P-12: $x=13, m+l=5.4$ P-13: $x=13, m+l=6$

Scheme 1: Synthesis of poly[oxyethylene(aminophosphonate-coH-phosphonate)]s P-12 and P-13.

spectrum of P-12 measured in DMSO- $\mathrm{d}_{6}$, the signal of $\mathrm{NH}$ proton appears at $4.60 \mathrm{ppm}$ as a broad singlet. The signals for the anthracene protons (AnthH) of $\mathbf{P - 1 2}$ and $\mathbf{P}-\mathbf{1 3}$ are found in the expected region of the spectra $[20,25] .{ }^{1} \mathrm{H}$ NMR spectra of $\mathbf{P - 1 2}$ and $\mathbf{P}-\mathbf{1 3}$ reveal two different doublet signals with large coupling constants that are due to the $\mathrm{PH}$ proton from $\mathrm{H}$-phosphonate repeating units and $\mathrm{PH}(\mathrm{O}) \mathrm{OH}$ end groups, respectively. ${ }^{13} \mathrm{C}\left\{{ }^{1} \mathrm{H}\right\}$ NMR spectrum of $\mathbf{P}-\mathbf{1 2}$ shows the signal of CHP carbon atom as a doublet at $54.79 \mathrm{ppm}$ with a large coupling constant $\left({ }^{1} J_{\mathrm{PC}}=159.7 \mathrm{~Hz}\right)$. The spectrum exhibits three distinct doublet signals which belong to the methylene carbon of the $\mathrm{POCH}_{2} \mathrm{CH}_{2}$ fragment from $\mathrm{H}$-phosphonate and aminophosphonate repeating units and of the $\mathrm{POCH}_{2}$ group from $\mathrm{H}$-phosphonate repeating units. The carbon signals of the nonequivalent $\mathrm{POCH}_{2}$ groups from aminophosphonate repeating units appear as two doublets. The methylene $\mathrm{CH}_{2}$ Fur carbon gives a doublet signal at $44.36 \mathrm{ppm}$. The HSQC spectrum shows the connection between this doublet and the proton signals at 3.66 and $3.42 \mathrm{ppm}$. These two signals are overlapped with the complex multiplet attributed to the $\mathrm{OCH}_{2} \mathrm{CH}_{2}, \mathrm{POCH}_{2} \mathrm{CH}_{2}$, and $\mathrm{OCH}_{3}$ proton signals of $\mathbf{P}-\mathbf{1 2}$. The signals for the furan protons (P-12 and $\mathbf{P}-13)$ and for the furan carbons (P-12) are also observed in the ${ }^{1} \mathrm{H}$ and ${ }^{13} \mathrm{C}$ NMR spectra, respectively. The assignment of the anthracene carbons of $\mathbf{P - 1 2}$ is based on the analysis of the HSQC spectrum and is in accordance with the data of similar aminophosphonate derivatives $[20,25] .{ }^{31} \mathrm{P}\left\{{ }^{1} \mathrm{H}\right\}$ NMR spectra of the products, taken in $\mathrm{CDCl}_{3}$ (P-12 and $\left.\mathbf{P}-\mathbf{1 3}\right)$ and DMSO- $\mathrm{d}_{6}(\mathbf{P}-\mathbf{1 2})$ solutions, display a singlet signal about $25 \mathrm{ppm}$ and another 
singlet in the range of 9.26-9.81 ppm, which are due to the phosphorus atoms of CHP and PH groups from the aminophosphonate and $\mathrm{H}$-phosphonate repeating units, respectively. Singlet signals for the phosphorus atom of CHP $(\mathrm{O}) \mathrm{H}, \mathrm{PH}(\mathrm{O}) \mathrm{OCH}_{3}$, and $\mathrm{PH}(\mathrm{O}) \mathrm{OH}$ end groups are observed in the spectra. The monoester end groups are generated through the addition of the $\mathrm{PH}(\mathrm{O}) \mathrm{OH}$ end groups in the starting polymer to the Schiff base [20]. The signal of the nonreacted $\mathrm{PH}(\mathrm{O}) \mathrm{OH}$ groups is found up field (5.01$2.42 \mathrm{ppm}$ ) in the spectra. In the coupled spectra, this signal appears as a doublet with coupling constant $\left({ }^{1} J_{\mathrm{PH}}\right)$ 647$610 \mathrm{~Hz}$, which indicates that these groups possess an ionic structure. The phosphorus atom from CHP diester end groups gives two distinct singlets with very close chemical shifts because of the presence of more than one diastereomeric species in the molecules of the products. On the basis of the ${ }^{31} \mathrm{P}\left\{{ }^{1} \mathrm{H}\right\}$ NMR spectra is estimated the average degree of polymerization of the starting polyphosphoester $1(n=6)$ and of the synthesized homologous polyphosphoesters P-12 $(m+l=5.4)$ and P-13 $(m+l=6)$. From the ${ }^{31} \mathrm{P}\left\{{ }^{1} \mathrm{H}\right\}$ NMR spectral data is calculated the content of the aminophosphonate units in the products: $54 \%$ (P-12) and $81 \%(\mathbf{P}-13)$. The fluorescence spectra of the synthesized homologues show that the emission maxima appear in the region $402-446 \mathrm{~nm}$. The mass spectra of the polyphosphoesters $\mathbf{P}-\mathbf{1 2}$ and $\mathbf{P}-\mathbf{1 3}$ are performed using electron impact mass spectrometry of the products in acetonitrile/water solutions. The analysis of the spectra reveals that they undergo strong fragmentation processes, which cause cleavages of their polymer backbones. The most intense peak (basic peak) in both spectra observed at $\mathrm{m} / z=286.1218(\mathbf{P}-12)$ and $286.1216(\mathbf{P}-13)$ can be assigned to the ion $\mathrm{C}_{20} \mathrm{H}_{16} \mathrm{~N}^{+} \mathrm{O}$ (calcd 286.1226). The structure of this cation $\left[\mathrm{C}_{14} \mathrm{H}_{9} \mathrm{CH}=\mathrm{N}^{+} \mathrm{HCH}_{2} \mathrm{C}_{4} \mathrm{H}_{3} \mathrm{O}\right]$ corresponds to the protonated form of the starting Schiff base S-2: 9anthrylidene-furfurylamine cation. The mass spectra of the polyphosphoesters P-8-P-11, studied previously [20], showed base peaks for an ion $\left(\mathrm{C}_{22} \mathrm{H}_{18} \mathrm{~N}^{+}\right)$at about $296 \mathrm{Da}$ which structure was identical with the structure of the protonated synthetic precursor (protonated Schiff base S-1) of these polymers. In both cases, an electron elimination at the nitrogen atom and a break of the C-P bond of the anthracene-containing aminophosphonate moiety lead to the formation of the protonated forms of the starting Schiff bases S-2 and S-1, respectively. Many other peaks are observed in the mass spectra of $\mathbf{P}-\mathbf{1 2}$ and $\mathbf{P}-\mathbf{1 3}$ due to the fragmentation of the polymeric chains.

Recently, we described the synthesis and the in vitro antitumor activity against a panel of human epithelial cancer cell lines and the in vitro and in vivo safety evaluation of anthracene-derived low-molecular and polymeric aminophosphonates and their precursors [20, 25-28]: Schiff bases S-1 and S-2, $\alpha$-aminophosphonates A-3-A-6, bis-aminophosphonate B-6 (R, S diastereomer), and polyphosphoesters $\mathbf{P}-\mathbf{8}-\mathbf{P}-\mathbf{1 1}$, containing aminophosphonate units (Figure 1). The $\alpha$-aminophosphonates A-3 and A-4 [25] and the polyphosphoesters P-8-P-11 [20] have been synthesized from the anthracene-derived Schiff base S-1, while the compounds A-5 [25] and A-6 [28] have been prepared using the anthracene- and furan-containing Schiff base S-2. The racemic compound A-5 has been separated into its two enantiomers A-5a and $\mathbf{A}-\mathbf{5 b}$ by HPLC technique [28]. Among the studied compounds A-3-A-5, aminophosphonate $\mathbf{A}-\mathbf{5}$, bearing anthracene and furan ring, showed the best antitumor effects against all tested human epithelial cancer cell lines. This result provokes us to incorporate such aminophosphonate fragments, which contain anthracene and furan units, into polymer backbone to obtain novel polyphosphoesters $\mathbf{P}-\mathbf{1 2}$ and $\mathbf{P}-\mathbf{1 3}$. The polyphosphoesters $\mathbf{P}-\mathbf{8}-\mathbf{P}-\mathbf{1 3}$ have been synthesized on the basis of biodegradable polymer carriers, which possess repeating hydrolytically unstable phosphorus ester linkages in their backbone [22]. The polymers $\mathbf{P - 8}$ and $\mathbf{P}-\mathbf{1 0}$ are built only of aminophosphonate repeating units, while the copolymers $\mathbf{P}-\mathbf{9}$ and P-11-P-13 contain aminophosphonate and hydrophilic H-phosphonate links. The newly synthesized polyphosphoester P-12 and the previously synthesized anthracenederived compounds, including Schiff bases S-1 and S-2, $\alpha$-aminophosphonates A-3-A-6, bis-aminophosphonate B-6 (Figure 1), two enantiomers $\mathbf{A}-\mathbf{5} \mathbf{a}$ and $\mathbf{A}-\mathbf{5} \mathbf{b}$, and polyphosphoesters P-8-P-11 (Figure 1), have been tested for cytotoxicity against a panel of human tumor cell lines: HL-60, SKW-3, REH, and K-562 (Table 1).

2.2. Pharmacology. As evidenced by the data presented in Table 1, in all of the screened leukemic lines calculated $\mathrm{IC}_{50}$ values of the tested compounds vary substantially both within and between the series. Comparable cytotoxicity was noted only for the precursors (anthracene-based Schiff bases S-1 and S-2) with the highest sensitivity of the ALL (REH) cells. The encountered inhibitory concentrations of both compounds are similar to cisplatin's, whereas HL-60, SKW-3, and K-562 cells retained a far greater proliferative capacity under the same conditions. $\alpha$-Aminophosphonates (A3-A6) showed lesser consistency in the produced growth inhibitory effect against the tested leukemic cells. Highest cytotoxic potential in all in vitro tumor models was encountered with $\alpha$-aminophosphonate $\mathbf{A}-\mathbf{4}$ whose $\mathrm{IC}_{50}$ estimates correlate with those of the referent drug. The other anthracene-derivative carrying an identical aminophosphonate residue, that is, A-3, produced an in-between inhibitory effect inferior to cisplatin's in HL-60, SKW-3, and REH test systems, whereby the estimated equieffective concentration for the K-562 cells was 10- to 15fold that of the referent drug. The racemic compound A-5, obtained from the anthracene- and furan-containing Schiff base S-2, appeared least effective in terms of growth inhibition, whereas both corresponding enantiomers (A-5a and $\mathbf{A}-\mathbf{5 b}$ ) achieved markedly lower $\mathrm{IC}_{50}$ values, especially in the leukemic subtypes of lymphoid origin (SKW-3 and REH cells). The other anthracene- and furan-carrying $\alpha$-aminophosphonate congener, that is, A-6, delivered a moderate anticancer efficacy ranging between that of A-5 and both chiral isomers $\mathbf{A}-\mathbf{5} \mathbf{a}$ and $\mathbf{A}-\mathbf{5 b}$. The cytostatic activity of the same compound is evidenced to be essentially invariable in all of the tested cell lines (closely comparable $\mathrm{IC}_{50}$ values).

The bis-aminophosphonate B-6 (meso form) showed negligible cytostatic activity in all of the screened leukemic variants $\left(\mathrm{IC}_{50}>100\right)$. 
<smiles>[Y]/N=C\c1c2ccccc2cc2ccccc12</smiles>

S-1, S-2<smiles>[Y]N[C@H](c1c2ccccc2cc2ccccc12)P([R])(=O)O[R]</smiles>

A-3-A-6<smiles>CCOP(=O)(OCC)C(Nc1ccc(Cc2ccc(NC(c3c4ccccc4cc4ccccc34)P(=O)(OCC)OCC)cc2)cc1)c1c2ccccc2cc2ccccc12</smiles>

B-6<smiles>CC(C)(C)OCCOP(=O)(O)C([NH3+])c1c2ccccc2cc2ccccc12</smiles>

P-8: $x=13, n=12 ;$ P-10: $x=4, n=12$

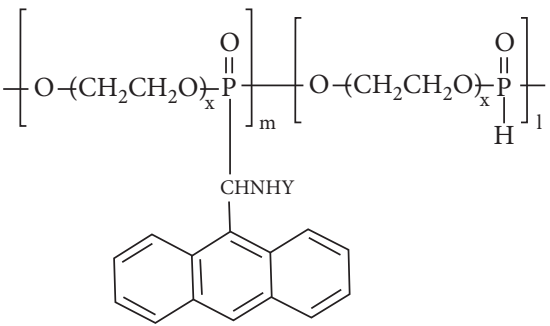

P-9: $x=13, m+l=12 ;$ P-11: $x=4, \mathrm{~m}+l=12$<smiles>[Y]Cc1ccco1</smiles>

Figure 1: Chemical structure of Schiff bases S-1 and S-2, $\alpha$-aminophosphonates A-3-A-6, bis-aminophosphonate B-6, and polyphosphoesters P-8-P-11.

TABLE 1: In vitro cytotoxicity (mean $\mathrm{IC}_{50}$ values, $[\mu \mathrm{M}] \pm \mathrm{SD}$ ) of the tested compounds and the referent drug cisplatin against the human leukemic lines HL-60, SKW-3, REH, and K-562.

\begin{tabular}{lcccc}
\hline & \multicolumn{4}{c}{$\mathrm{IC}_{50}(\mu \mathrm{M})$} \\
Compounds & HL-60 & SKW-3 & REH & K-562 \\
& (APML) & (CLL) & (ALL) & $(\mathrm{CML})$ \\
\hline S-1 & $47.7 \pm 6.9$ & $57.2 \pm 4.6$ & $19.8 \pm 2.7$ & $80.8 \pm 11.4$ \\
S-2 & $37.3 \pm 4.6$ & $34.3 \pm 7.1$ & $18.3 \pm 3.2$ & $89.7 \pm 9.1$ \\
A-3 & $35.6 \pm 6.1$ & $37.0 \pm 5.6$ & $30.5 \pm 7.8$ & $>200$ \\
A-4 & $\mathbf{2 1 . 2} \pm \mathbf{4 . 4}$ & $\mathbf{8 . 4} \pm \mathbf{1 . 5}$ & $\mathbf{1 4 . 1} \pm \mathbf{1 . 9}$ & $\mathbf{1 8 . 7} \pm \mathbf{4 . 9}$ \\
A-5 & $76.8 \pm 12.9$ & $76.3 \pm 7.9$ & $114.8 \pm 14.7$ & $139.1 \pm 8.1$ \\
A-6 & $64.1 \pm 9.8$ & $51.4 \pm 7.3$ & $42.8 \pm 6.9$ & $47.3 \pm 6.5$ \\
A-5a & $30.2 \pm 2.1$ & $10.5 \pm 2.5$ & $21.4 \pm 0.7$ & $58.6 \pm 2.0$ \\
A-5b & $30.3 \pm 2.1$ & $20.5 \pm 2.0$ & $17.6 \pm 0.8$ & $79.7 \pm 3.3$ \\
B-6 & $139.1 \pm 11.3$ & $187.2 \pm 14.4$ & $165.9 \pm 21.5$ & $>200$ \\
P-8 & $\mathbf{2 . 1} \pm \mathbf{0 . 6}$ & $\mathbf{3 . 1} \pm \mathbf{1 . 2}$ & $7.9 \pm \mathbf{1 . 4}$ & $\mathbf{3 5 . 6} \pm \mathbf{7 . 3}$ \\
P-9 & $\mathbf{5 . 5} \pm \mathbf{1 . 2}$ & $\mathbf{5 . 4} \pm \mathbf{1 . 2}$ & $\mathbf{1 6 . 8} \pm \mathbf{1 . 2}$ & $\mathbf{2 4 . 8} \pm \mathbf{1 . 1}$ \\
P-10 & $49.4 \pm 7.3$ & $38.5 \pm 4.3$ & $98.7 \pm 8.8$ & $163.0 \pm 22.3$ \\
P-11 & $116.9 \pm 10.4$ & $61.1 \pm 9.2$ & $113.4 \pm 10.5$ & $>200$ \\
P-12 & $40.1 \pm 7.6$ & $29.5 \pm 5.2$ & $33.8 \pm 6.4$ & $26.9 \pm 5.9$ \\
Cisplatin & $\mathbf{8 . 1} \pm \mathbf{1 . 7}$ & $\mathbf{1 1 . 2} \pm \mathbf{0 . 8}$ & $\mathbf{1 7 . 2} \pm \mathbf{2 . 1}$ & $\mathbf{1 8 . 6} \pm \mathbf{3 . 9}$ \\
\hline APHL acute & &
\end{tabular}

APML: acute promyeloid leukemia; CLL: chronic lymphocytic leukemia; ALL: acute lymphoid leukemia; CML: chronic myelocytic leukemia.

In line with the A-4 toxicity profile, the polymeric derivatives, that is, polyphosphoesters $\mathbf{P}-\mathbf{8}$ and $\mathbf{P}-\mathbf{9}$, yielded distinctly lower equally effective concentrations in all four tumor lines as compared to the newly synthesized P-12. Cytotoxicity of both $\mathbf{P}-\mathbf{8}$ and $\mathbf{P}-\mathbf{9}$ is largely surpassing that of cisplatin in HL-60 and SKW-3 and 2-fold higher (P-8) or equal (P-9) to the referent in REH cells, whereas the chronic myeloid cell line K-562 displayed 2-fold lower chemosensitivity towards $\mathbf{P - 8}$ as compared to the referent drug. The same leukemic line showed a slightly lower responsiveness towards the P-9 analogue, however estimated $\mathrm{IC}_{50}$ value remaining in the range of cisplatin's. The other two polyphosphoesters, namely, $\mathbf{P}-\mathbf{1 0}$ and $\mathbf{P}-\mathbf{1 1}$, bearing the same aminophosphonate residue and a shorter length of the PEG (4 units) chain demonstrated poor cytostatic activity, whereby the K-562 cell line was rated again as the least sensitive one. The newly synthesized $\mathbf{P}-\mathbf{1 2}$ showed consistently lower cytotoxicity than cisplatin that was oddly most pronounced in the CML K-562 cells, followed by the SKW-3, REH, and HL-60 myeloproliferative cell lines.

Overall tumor-inhibiting activity of the studied anthracene derivatives varies by compound and cell line, albeit some correlation was observed between cancer chemosensitivity and number and type of polymer units. The promyelocytic and T-cell leukemic cell lines (HL-60 and SKW-3 cells, respectively) were generally more sensitive to the $\alpha$-aminophosphonates A-3 and A-4 than to the Schiff bases, whereas the latter exerted substantially stronger cytotoxic effects against the B-cell lymphoma cell line (REH). The most potent low-molecular analogue in the tested panel of human leukemic cell lines was the $\alpha$-aminophosphonate $\mathbf{A}-\mathbf{4}$, whereas highest cytotoxicity among the polymeric species was determined for the corresponding polyphosphoester P-8. In the K-562 cell line, the newly synthesized polyphosphoesters P-12 demonstrated cytotoxicity matching that of the leader polymers P-8 and P-9 as well as the reference drug, while a fewfold variability in tumor cell response was established for the rest of the leukemic lines. The data for $\mathrm{P}-12$, given in Table 1 , 
show that the immobilization of anthracene- and furancontaining aminophosphonate units into the polymer chain results in a higher cytotoxicity of the polymer against the tested human leukemic cell lines compared to that of its low-molecular analogues A-5 and A-6. However, polymer P-12 exhibits moderate cytotoxicity compared to polymers P-8 and P-9. The novel polyphosphoesters P-12 and P-13 will be of interest for future investigation on human epithelial cancer cell lines, based on the results of their lowmolecular analogue (A-5) obtained from its study with such cancer cell lines [25].

Among the all tested compounds, we considered that aminophosphonate A-4 and, especially, polymers P-8 and P-9 appear very promising new materials for development of anticancer drugs.

\section{Conclusion}

Two novel homologous polyphosphoesters containing anthracene- and furan-derived aminophosphonate moieties, poly[oxyethylene(aminophosphonate-co-H-phosphonate)]s P-12 and P-13, were synthesized through an addition of poly (oxyethylene H-phosphonate) 1 to the Schiff base 9anthrylidene-furfurylamine $\mathbf{S - 2}$. The reaction was carried out by conventional heating $(\mathbf{P}-\mathbf{1 2})$ and under microwave irradiation $(\mathbf{P}-\mathbf{1 3})$ of the reagents. It was conducted using an excess of the Schiff base and in the presence of a catalytic amount of $\mathrm{CdI}_{2}$. The structure of the polyphosphoesters was studied by means of spectral methods: IR, NMR $\left({ }^{1} \mathrm{H},{ }^{13} \mathrm{C}\right.$, and ${ }^{31} \mathrm{P}$ ), fluorescence, and mass spectra. The average degree of polymerization of the starting polyphosphoester $\mathbf{1}$ and of the synthesized polyphosphoesters $\mathbf{P}-\mathbf{1 2}$ and $\mathbf{P}-\mathbf{1 3}$ and the ratio between the aminophosphonate and the H-phosphonate units in the products were estimated from their ${ }^{31} \mathrm{P}\left\{{ }^{1} \mathrm{H}\right\}$ NMR spectral data.

The novel polyphosphoester P-12 and some anthracenederived compounds, among them, the $\alpha$-aminophosphonates A-3-A-6, their precursors the Schiff bases S-1 and S-2, the bis-aminophosphonate B-6, the two enantiomers A-5a and A-5b of the racemic A-5, and the polyphosphoesters P-8P-11, containing aminophosphonate units, have been tested for cytotoxicity against a panel of human tumor cell lines: HL60, SKW-3, REH, and K-562. Both precursors S-1 and S-2 presented similar cytotoxicity profiles that are cisplatin-like only in the REH lymphoid cell line. Leader compound of the $\alpha$-aminophosphonates A-3-A-6 is A-4 with cell deathinducing properties fully equaling those of the referent drug. Some of the polymeric analogues elicited moderate (P10 and $\mathbf{P}-\mathbf{1 2})$ to low (P-11) cytotoxic activity, whereas the polyphosphoesters $\mathbf{P}-\mathbf{8}$ and $\mathbf{P}-\mathbf{9}$ produced in vitro antitumor effects largely surpassing cisplatin's potency. Three of the tested compounds, namely, $\mathbf{P - 8}, \mathbf{P}-\mathbf{9}$, and $\mathbf{A - 4}$, appear quite promising as new materials for the development of drug in chemotherapy of malignant leukemic diseases.

\section{Experimental}

4.1. Synthesis. Dimethyl H-phosphonate (Sigma-Aldrich Chemie $\mathrm{GmbH}$, Steinheim, Germany) was purified by vacuum distillation. Poly(ethylene glycol) with average molecular weight $600 \mathrm{Da}$ (PEG 600) was purchased from Fluka and dried prior to use. All solvents were freshly distilled before use. IR spectra were taken on an IRAffinity-1 spectrophotometer. ${ }^{1} \mathrm{H},{ }^{13} \mathrm{C}\left\{{ }^{1} \mathrm{H}\right\}$, and HSQC NMR spectra of polymer P-12 in $\mathrm{CDCl}_{3}$ were recorded on an Avance $600 \mathrm{MHz}$ spectrometer at room temperature and tetramethylsilane (TMS) was used as an internal standard. ${ }^{1} \mathrm{H}$ NMR spectra of $\mathbf{P}-\mathbf{1 2}$ in DMSO- $\mathrm{d}_{6}$ and $\mathbf{P}-\mathbf{1 3}$ in $\mathrm{CDCl}_{3}$ were taken on a Bruker DRX-250 $250 \mathrm{MHz}$ spectrometer at room temperature and TMS was used as an internal standard. ${ }^{31} \mathrm{P}$ NMR spectra of P-12 in $\mathrm{CDCl}_{3}$ and DMSO- $\mathrm{d}_{6}$ solutions and of $\mathbf{P}-\mathbf{1 3}$ in $\mathrm{CDCl}_{3}$ were registered on an Avance $600 \mathrm{MHz}$ (P-12) and on a Bruker DRX-250 $250 \mathrm{MHz}$ (P-13) spectrometers, using $85 \% \mathrm{H}_{3} \mathrm{PO}_{4}$ as an external standard. Fluorescence spectra were recorded on a JascoFp 6600 fluorometer (220-750 $\mathrm{nm}$ excitation range/220-1010 $\mathrm{nm}$ emission range). Microwave-assisted reaction was carried out in Microwave Reactor ROTOSYNTH Rotativ Solid Phase purchased from Milestone, Bergamo, Italy. The mass spectra were taken on Thermo Scientific Q Exactive Plus (Bremen, Germany) equipped with heated electrospray probe HESI-II in positive mode. The instrument operated in fullscan mode in $\mathrm{m} / z$ range 200-3000 at resolution 280000 (at $\mathrm{m} / z$ 200). The instrument parameters were as follows: spray voltage $3.5 \mathrm{kV}$, sheath gas 36 psi, auxiliary gas 11 a.u., ion transfer tube temperature $320^{\circ} \mathrm{C}$, and HESI-II vaporizer temperature $320^{\circ} \mathrm{C}$. Data acquisition and processing was done using Thermo Scientific Xcalibur ver. 3. All solvents were of LC-MS grade and were purchased from Thermo Fisher Scientific (Waltham, USA).

4.1.1. Schiff Bases $S-1$ and S-2. 9-Anthrylidene-p-toluidine S-1 $[25,29]$ and 9-anthrylidene-furfurylamine $\mathbf{S}-\mathbf{2}[25,28]$ were prepared following previously described procedures.

4.1.2. $\alpha$-Aminophosphonates $\boldsymbol{A}-\mathbf{3}-\boldsymbol{A}$-6. $N$-methyl(dimethoxyphosphonyl)-1-(9-anthryl)]-p-toluidine A-3 [25], [N-methyl(diethoxyphosphonyl)-1-(9-anthryl)]-p-toluidine A-4 [25], [N-methyl(diethoxyphosphonyl)-1-(9-anthryl)] furfurylamine A-5 [25], and [N-methyl(dimethoxyphosphonyl)-1-(9-anthryl)]furfurylamine A-6 [28] were obtained according to procedures described earlier.

4.1.3. Enantiomers $\boldsymbol{A}-\mathbf{5} \boldsymbol{a}$ and $\boldsymbol{A}-\mathbf{5} \boldsymbol{b}$. The enantioseparation of the racemic $\alpha$-aminophosphonate $\mathbf{A}-\mathbf{5}$ into its enantiomers $\mathbf{A}-\mathbf{5} \mathbf{a}$ and $\mathbf{A}-\mathbf{5 b}$ was reported in a previous paper [28] $\mathbf{A}-\mathbf{5 a}$, $[\alpha]_{\mathrm{D}}{ }^{23}=-14.30^{\circ} \quad\left(c=1.00, \mathrm{CHCl}_{3}\right)$ and $\mathbf{A}-5 \mathbf{b}, \quad[\alpha]_{\mathrm{D}}{ }^{23}=$ $+16.90^{\circ}\left(c=1.00, \mathrm{CHCl}_{3}\right)$.

4.1.4. Bis-aminophosphonate B-6. $4.4^{\prime}$-Bis $[N$-methyl(diethoxyphosphonyl)-1-(9-anthryl)]diaminodiphenylmethane B-6 was prepared as previously described [26].

4.1.5. Polyphosphoesters Containing Anthracene-Derived Aminophosphonate Units P-8-P-11: Polyloxyethylene 
aminophosphonate)s $\mathbf{P - 8}$ and $\mathbf{P}-\mathbf{1 0}$ and Poly[oxyethylene (aminophosphonate-co-H-phosphonate)]s $\quad \mathbf{P - 9}$ and P-11. The polymers P-8-P-11 were obtained through an addition reaction of poly(oxyethylene H-phosphonate)s to the Schiff base S-1 using synthetic procedures reported previously [20]. The polymers P-8 and P-9 were synthesized from polymeric $\mathrm{H}$-phosphonate based on PEG 600 and polymers P-10 and P-11 based on PEG 200. The content of the aminophosphonate units in the polymers is as follows: $90 \%$ (P-8), 100\% (P-10), 43\% (P-9), and 13\% (P-11).

4.1.6. Polyphosphoesters Containing Anthracene- and FuranDerived Aminophosphonate Units P-12 and P-13

(1) Poly(oxyethylene H-phosphonate) 1. Poly(oxyethylene H-phosphonate) 1 ( $x=13$, average degree of polymerization $n=6$, number average molecular weight $\mathrm{Mn}=4550 \mathrm{Da}$ ) was prepared via a polytransesterification reaction of dimethyl $\mathrm{H}$-phosphonate and poly(ethylene glycol) with number average molecular weight $600 \mathrm{Da}$ (PEG 600) according to literature methods $[30,31]$.

(2) Poly[oxyethylene(aminophosphonate-co-H-phosphonate)] P-12. Poly(oxyethylene H-phosphonate) $1, \mathrm{Mn}=4550 \mathrm{Da}$ $(3.38 \mathrm{~g}, 5.31 \mathrm{mmol}$ repeating units) dissolved in toluene $(20 \mathrm{ml})$, and $\mathrm{CdI}_{2}(0.04 \mathrm{~g}, 0.11 \mathrm{mmol})$ were placed in a flask equipped with a magnetic stirrer, a thermometer, an inlet for inert gas, and a reflux condenser. The mixture was stirred for a half an hour at room temperature for dissolving the catalyst. Then a solution of 9-anthrylidene-furfurylamine S-2 $(1.94 \mathrm{~g}, 6.80 \mathrm{mmol})$ in toluene $(10 \mathrm{ml})$ was added and the reaction mixture was heated at $60^{\circ} \mathrm{C}$ for $25 \mathrm{~h}$ with stirring. After removal of the toluene in vacuum and cooling to room temperature, the crude product was washed with dry diethyl ether, precipitated three times in dry diethyl ether from a toluene solution, and dried under reduce pressure to constant weight. The polymer $\mathbf{P}-\mathbf{1 2}$ is viscous oil. Yield: $3.40 \mathrm{~g}(69 \%)$; aminophosphonate units $=54 \% ; \mathrm{Mn}=5800$. IR (neat), $v\left(\mathrm{~cm}^{-1}\right): 3343\left(\nu_{\mathrm{NH}}\right), 2355\left(\nu_{\mathrm{PH}}\right), 1248\left(\nu_{\mathrm{P}=\mathrm{O}}\right), 1095$ $\left(\nu_{\text {P-O-C }}\right)$. Fluorescence spectrum: Ex $395 \mathrm{~nm}-\lambda_{\max }=402 \mathrm{~nm}$, $422 \mathrm{~nm}, 445 \mathrm{~nm} .{ }^{1} \mathrm{H}$ NMR, $\delta(\mathrm{ppm}), J_{\mathrm{HH}}(\mathrm{Hz}), J_{\mathrm{PH}}(\mathrm{Hz})$. Solvent $\mathrm{CDCl}_{3}$ : $9.24\left(\mathrm{~d},{ }^{3} J=9.0\right.$, AnthH- $\alpha$ ), 8.37 (AnthH-10), $8.04\left(\mathrm{~d},{ }^{3} J=8.7\right.$, AnthH- $\alpha$ ), 7.93 (AnthH- $\alpha$ ), 7.92 (AnthH- $\alpha$ ), 7.42 (m, AnthH- $\beta$ ), 7.16 (FurH-5), 6.88 (d, ${ }^{1} J=714.4$, $\mathrm{PH}$ repeating unit), $6.77\left(\mathrm{~d},{ }^{1} J=647.4, \mathrm{PH}(\mathrm{O}) \mathrm{OH}\right.$ end group), 6.12 (FurH-4), 5.82 (FurH-3), $5.68\left(\mathrm{~d},{ }^{2} J=23.5\right.$, CHP), $4.20-3.76\left(\mathrm{~m}, \mathrm{POCH}_{2}\right), 3.68-2.96\left(\mathrm{~m}, \mathrm{OCH}_{2} \mathrm{CH}_{2}\right.$, $\mathrm{POCH}_{2} \mathrm{CH}_{2}, \mathrm{CH}_{2}$ Fur, $\left.\mathrm{OCH}_{3}\right)$. Solvent $\mathrm{DMSO}_{6}: \mathrm{d}_{6}: 9.22$ (AnthH- $\alpha$ ), 8.61 (AnthH-10), 8.12 (AnthH- $\alpha), 8.10$ (AnthH- $\alpha$ ), 8.08 (AnthH- $\alpha$ ), 7.54 (m, AnthH- $\beta$ ), 7.46 (dd, ${ }^{3} J=1.8,{ }^{4} J=0.8$, FurH-5), 6.85 (d, ${ }^{1} J=726.7$, PH repeating unit), $6.64\left(\mathrm{~d},{ }^{1} J=587.0, \mathrm{PH}(\mathrm{O}) \mathrm{OH}\right.$ end group), 6.32 (dd, ${ }^{3} J=3.1$ and 1.8, FurH-4), 6.03 (FurH-3), $5.71\left(\mathrm{~d},{ }^{2} J=23.4\right.$, CHP), 4.60 (br.s, NH), 4.13, 3.68, and $3.17\left(3 \mathrm{~m}, \mathrm{POCH}_{2}\right.$, $\mathrm{OCH}_{2} \mathrm{CH}_{2}, \mathrm{POCH}_{2} \mathrm{CH}_{2}, \mathrm{CH}_{2}$ Fur, $\left.\mathrm{OCH}_{3}\right) .{ }^{13} \mathrm{C}\left\{{ }^{1} \mathrm{H}\right\}$ NMR $\left(\mathrm{CDCl}_{3}\right), \quad \delta(\mathrm{ppm}), \bar{J}_{\mathrm{PC}}(\mathrm{Hz}): 152.85$ (FurC-2), 141.96 (FurC-5), 129.34 (AnthC- $\alpha$ ), 128.93 (d, ${ }^{5} J=4.5$, AnthC-10), 128.88 (AnthC- $\alpha$ ), 127.44 (AnthC- $\alpha$ ), 126.26, 125.55, 125.24, and 124.68 (AnthC- $\beta$ ), 123.68 (AnthC- $\alpha$ ), 110.04 (FurC-4), 108.04 (FurC-3), 70.53 and $70.42\left(\mathrm{OCH}_{2} \mathrm{CH}_{2}\right), 70.15$ (d, ${ }^{3} \mathrm{~J}=5.4, \mathrm{POCH}_{2} \mathrm{CH}_{2}, \mathrm{H}$-phosphonate unit), 69.81 (d, ${ }^{3} J=5.9, \mathrm{POCH}_{2} \mathrm{CH}_{2}$, aminophosphonate unit), 65.54 and $65.40\left(2 \mathrm{~d},{ }^{2} J=7.2\right.$ and 7.2, $\mathrm{POCH}_{2}$, aminophosphonate unit), 64.70 (d, ${ }^{2} J=6.1, \mathrm{POCH}_{2}, \mathrm{H}$-phosphonate unit), 54.79 (d, $\left.{ }^{1} J=159.7, \mathrm{CHP}\right), 44.36\left(\mathrm{~d},{ }^{3} \mathrm{~J}=16.0, \mathrm{FurCH}_{2}\right) .{ }^{31} \mathrm{P}\left\{{ }^{1} \mathrm{H}\right\}$ NMR, $\delta$ (ppm). Solvent $\mathrm{CDCl}_{3}: 26.23$ and $26.11(2 \mathrm{~s}$, CHP diester end group), 25.44 (s, CHP repeating unit), 22.40 (s, $\mathrm{CHP}(\mathrm{O}) \mathrm{OH}$ end group), $10.00\left(\mathrm{~s}, \mathrm{PH}(\mathrm{O}) \mathrm{OCH}_{3}\right.$ end group), 9.31 (s, $\mathrm{PH}$ repeating unit), $4.88(\mathrm{~s}, \mathrm{PH}(\mathrm{O}) \mathrm{OH}$ end group). Solvent DMSO-d $\mathrm{d}_{6}: 25.94$ (s, CHP diester end group), 25.01 (s, CHP repeating unit), 21.80 (s, $\mathrm{CHP}(\mathrm{O}) \mathrm{OH}$ end group), 9.81 (s, PH repeating unit), 2.42 (s, $\mathrm{PH}(\mathrm{O}) \mathrm{OH}$ end group). ES-MS: $m / z=286.1218 \mathrm{C}_{20} \mathrm{H}_{16} \mathrm{~N}^{+} \mathrm{O}$ (calcd 286.1226).

(3) Poly[oxyethylene (aminophosphonate-co-H-phosphonate)] P-13. Poly (oxyethylene $\mathrm{H}$-phosphonate) $\mathbf{1}, \mathrm{Mn}=$ $4550 \mathrm{Da}(1.66 \mathrm{~g}, 2.61 \mathrm{mmol}$ repeating units) dissolved in toluene $(15 \mathrm{ml})$, and $\mathrm{CdI}_{2}(0.02 \mathrm{~g}, 0.05 \mathrm{mmol})$ were placed in a flask equipped with a magnetic stirrer, a thermometer, an inlet for inert gas, and a reflux condenser. The catalyst was dissolved by stirring at room temperature for a half an hour. Then a solution of 9-anthrylidene-furfurylamine S-2 $(0.95 \mathrm{~g}$, $3.33 \mathrm{mmol})$ in toluene $(10 \mathrm{ml})$ was added and the reaction mixture was microwave irradiated $(250 \mathrm{~W})$ at a hold temperature $34^{\circ} \mathrm{C}$ (read by IR thermometer) in an open vessel for an hour. After removal of the toluene in vacuum and cooling to room temperature, the crude product was purified following the procedure given for P-12. The polymer P-13 is viscous oil. Yield: $2.11 \mathrm{~g}(88 \%)$; aminophosphonate units $=81 \% ; \mathrm{Mn}=6700$. IR (neat), $v\left(\mathrm{~cm}^{-1}\right): 3339\left(\nu_{\mathrm{NH}}\right), 2361$ $\left(\nu_{\mathrm{PH}}\right), 1247\left(\nu_{\mathrm{P}=\mathrm{O}}\right), 1093$ ( $\left.\nu_{\mathrm{P}-\mathrm{O}-\mathrm{C}}\right)$. Fluorescence spectrum: Ex $375 \mathrm{~nm}-\lambda_{\max }=403 \mathrm{~nm}, 425 \mathrm{~nm}, 446 \mathrm{~nm} .{ }^{1} \mathrm{H} \mathrm{NMR}\left(\mathrm{CDCl}_{3}\right)$, $\delta(\mathrm{ppm}), J_{\mathrm{HH}}(\mathrm{Hz}), J_{\mathrm{PH}}(\mathrm{Hz}): 9.24\left(\mathrm{~d},{ }^{3} J=9.1\right.$, AnthH- $\left.\alpha\right), 8.37$ (d, ${ }^{6} J=2.4$, AnthH-10), 8.04 (d, ${ }^{3} J=7.9$, AnthH- $\alpha$ ), 7.94 (AnthH- $\alpha$ ), 7.91 (AnthH- $\alpha$ ), 7.43 (m, AnthH- $\beta$ ), 7.16 (FurH5), $6.88\left(\mathrm{~d},{ }^{1} J=716.3\right.$, PH repeating unit), $6.74\left(\mathrm{~d},{ }^{1} J=674.1\right.$, $\mathrm{PH}(\mathrm{O}) \mathrm{OH}$ end group), 6.12 (dd, ${ }^{3} J=3.0$ and 1.9, FurH-4), $5.82\left(\mathrm{~d},{ }^{3} J=3.0\right.$, FurH-3), $5.69\left(\mathrm{~d},{ }^{2} J=23.6\right.$, CHP $), 4.26-3.69$ $\left(\mathrm{m}, \mathrm{POCH}_{2}\right), \quad 3.67-2.80\left(\mathrm{~m}, \mathrm{OCH}_{2} \mathrm{CH}_{2}, \mathrm{POCH}_{2} \mathrm{CH}_{2}\right.$, $\mathrm{CH}_{2}$ Fur, $\left.\mathrm{OCH}_{3}\right),{ }^{31} \mathrm{P}\left\{{ }^{1} \mathrm{H}\right\}$ NMR $\left(\mathrm{CDCl}_{3}\right), \delta$ (ppm): 26.23 and 26.11 ( $2 \mathrm{~s}$, CHP diester end group), 25.44 (s, CHP repeating unit), 22.39 (s, $\mathrm{CHP}(\mathrm{O}) \mathrm{OH}$ end group), 10.00 (s, $\mathrm{PH}(\mathrm{O})$ $\mathrm{OCH}_{3}$ end group), 9.26 (s, PH repeating unit), 5.01 (s, PH (O)OH end group). ES-MS: $m / z=286.1216 \mathrm{C}_{20} \mathrm{H}_{16} \mathrm{~N}^{+} \mathrm{O}$ (calcd 286.1226).

\subsection{Pharmacology}

4.2.1. MTT Dye Reduction Assay. Anticancer activity of the investigational compounds was determined using a standard MTT-based colorimetric assay for evaluating cell viability. In brief, exponential-phased suspension leukemic cells were harvested and seeded $(100 \mu \mathrm{l} /$ well $)$ in 96 -well plates at the appropriate density, that is, $3 \times 10^{5}$. Following a $24 \mathrm{~h}$ incubation, cells were treated with serial dilutions of the tested 
substances in an appropriate concentration range. Following exposure time of $72 \mathrm{~h}$, filter sterilized MTT substrate solution $(5 \mathrm{mg} / \mathrm{ml}$ in PBS) was added to each well of the culture plate. A further 1- to 4-hour incubation allowed formation of purple insoluble precipitates of the formazan dye. The latter were dissolved in isopropyl alcohol solution containing 5\% formic acid prior to absorbance measurement at $550 \mathrm{~nm}$. Collected absorbance values were blanked against MTT and isopropanol solution and normalized to the mean value of untreated control (100\% cell viability).

\section{Data Availability}

The data used to support the findings of this study are available from the corresponding author upon request. All information about the materials and data is available from the collaborating scientists involved with the research submitted for publication upon request.

\section{Conflicts of Interest}

The authors declare that there are no conflicts of interest regarding the publication of this paper.

\section{Acknowledgments}

Thanks are due to the Bulgarian National Science Fund of Ministry of Education and Science for the financial support (Contract no. DTK-02/34).

\section{References}

[1] R. A. Cherkasov and V. I. Galkin, "The Kabachnik-Fields reaction: synthetic potential and the problem of the mechanism," Russian Chemical Reviews, vol. 67, no. 10, pp. 857-882, 1998.

[2] J. Huang and R. Chen, "An overview of recent advances on the synthesis and biological activity of $\alpha$-aminophosphonic acid derivatives," Heteroatom Chemistry, vol. 11, no. 7, pp. 480492,2000

[3] N. Long, X.-J. Cai, B.-A. Song et al., "Synthesis and antiviral activities of cyanoacrylate derivatives containing an $\alpha$-aminophosphonate moiety," Journal of Agricultural and Food Chemistry, vol. 56, no. 13, pp. 5242-5246, 2008.

[4] J. Galezowska and E. Gumienna-Kontecka, "Phosphonates, their complexes and bio-applications: a spectrum of surprising diversity," Coordination Chemistry Reviews, vol. 256, no. 1-2, pp. 105-124, 2012.

[5] H. R. Hudson, "Aminophosphonic and aminophosphinic acids and their derivatives as agrochemicals," in Aminophosphonic and Aminophosphinic Acids Chemistry and Biological Activity, V. P. Kukhar and H. R. Hudson, Eds., pp. 443-481, John Wiley \& Sons, Chichester, UK, 2000.

[6] T. L. Rogers and I. Holen, "Tumour macrophages as potential targets of bisphosphonates," Journal of Translational Medicine, vol. 9, no. 1, p. 177, 2011.

[7] J. R. Green, "Antitumor effect of bisphosphonates," Cancer, vol. 97, no. S3, pp. 840-847, 2003.

[8] J. R. Green, "Anti-tumor potential of bisphosphonates," Medizinische Klinik, vol. 95, no. 2, pp. 23-28, 2000.
[9] I. C. Dormehl, W. K. A. Louw, R. J. Milner, E. Kilian, and F. H. A. Schneeweiss, "Biodistribution and pharmacokinetics of variously sized molecular radiolabelled polyethyleneiminomethyl phosphonic acid as a selective bone seeker for therapy in the normal primate model," Arzneimittelforschung, vol. 51, no. 3, pp. 258-263, 2011.

[10] L. J. Tušek-Božić, "Aminophosphonate metal complexes of biomedical potential," Current Medicinal Chemistry, vol. 20, no. 16, pp. 2096-2117, 2013.

[11] L. Gu and C. Jin, "Synthesis and antitumor activity of $\alpha$-aminophosphonates containing thiazole[5,4-b]pyridine moiety," Organic and Biomolecular Chemistry, vol. 10, no. 35, pp. 7098-7102, 2012.

[12] M. F. Abdel-Megeed, B. E. Badr, M. M. Azaam, and G. A. El-Hiti, "Synthesis, antimicrobial and anticancer activities of a novel series of diphenyl 1-(pyridin-3-yl)ethylphosphonates," Bioorganic and Medicinal Chemistry, vol. 20, no. 7, pp. 2252-2258, 2012.

[13] F. Bahrami, F. Panahi, F. Daneshgar, R. Yousefi, M. B. Shahsavani, and A. Khalafi-Nezhad, "Synthesis of new $\alpha$-aminophosphonate derivatives incorporating benzimidazole, theophylline and adenine nucleobases using L-cysteine functionalized magnetic nanoparticles (LCMNP) as magnetic reusable catalyst: evaluation of their anticancer properties," RSC Advances, vol. 6, no. 7, pp. 5915-5924, 2016.

[14] G. V. Shitre, R. S. Bhosale, D. S. Karhale et al., "Synthesis and biological evaluation of novel $\alpha$-aminophosphonate derivatives possessing thiazole-piperidine skeleton as cytotoxic agents," Chemistry and Biology Interface, vol. 4, no. 1, pp. 48-57, 2014.

[15] Y.-J. Li, C.-Y. Wang, M.-Y. Ye, G.-Y. Yao, and H.-S. Wang, "Novel coumarin-containing aminophosphonates as antitumor agent: synthesis, cytotoxicity, DNA-binding and apoptosis evaluation," Molecules, vol. 20, no. 8, pp. 14791-14809, 2015.

[16] X.-C. Huang, M. Wang, Y.-M. Pan, X.-Y. Tian, H.-S. Wang, and Y. Zhang, "Synthesis and antitumor activities of novel $\alpha$-aminophosphonates dehydroabietic acid derivatives," Bioorganic and Medicinal Chemistry Letters, vol. 23, no. 19, pp. 5283-5289, 2013.

[17] J.-M. Qin, J.-F. Li, M.-Y. Ye et al., "Synthesis and antitumor activities of novel diacerein $\alpha$-aminophosphonates conjugates," Indian Journal of Chemistry, vol. 53B, pp. 1584-1595, 2014.

[18] S. U. Deshmukh, K. R. Kharat, A. R. Yadav et al., "Synthesis of novel $\alpha$-aminophosphonate derivatives, biological evaluation as potent antiproliferative agents and molecular docking," Chemistry Select, vol. 3, no. 20, pp. 5552-5558, 2018.

[19] I. Kraicheva, A. Bogomilova, I. Tsacheva et al., "Synthesis, NMR characterization and in vitro cytotoxicity evaluation of new poly(oxyethylene aminophosphonate)s," European Journal of Medicinal Chemistry, vol. 45, no. 12, pp. 6039-6044, 2010.

[20] I. Kraicheva, E. Vodenicharova, S. Shenkov et al., "Synthesis, characterization, antitumor activity and safety testing of novel polyphosphoesters bearing anthracene-derived aminophosphonate units," Bioorganic and Medicinal Chemistry, vol. 22, no. 2, pp. 874-882, 2014.

[21] C. Elvira, A. Gallardo, J. San Roman, and A. Cifuentes, "Covalent polymer-drug conjugates," Molecules, vol. 10, no. 1, pp. 114-125, 2005.

[22] Z. Zhao, J. Wang, H.-Q. Mao, and K. W. Leong, "Polyphosphoesters in drug and gene delivery," Advanced Drug Delivery Reviews, vol. 55, no. 4, pp. 483-499, 2003. 
[23] J. Wang, Y.-Y. Yuan, and J.-Z. Du, "Polyphosphoesters: controlled ringpening polymerization and biological applications," in Polymer Science. A Comprehensive Reference, K. Matyaszewski and M. Moeller, Eds., vol. 4, pp. 719-745, B. V. Elsevier, Philadelphia, Netherlands, 2012.

[24] J. Luten, C. F. van Nostrum, S. C. De Smedt, and W. E. Hennink, "Biodegradable polymers as non-viral carriers for plasmid DNA delivery," Journal of Controled Release, vol. 126, no. 2, pp. 97-110, 2008.

[25] I. Kraicheva, I. Tsacheva, E. Vodenicharova et al., "Synthesis, antiproliferative activity and genotoxicity of novel anthracene-containing aminophosphonates and a new anthracene-derived Schiff base," Bioorganic and Medicinal Chemistry, vol. 20, no. 1, pp. 117-124, 2012.

[26] I. Kraicheva, E. Vodenicharova, E. Tashev et al., "Synthesis and NMR characterization of two novel anthracene-derived Bis(Aminophosphonate)s. Basic hydrolysis of some aminophosphonate derivatives," Phosphorus, Sulfur, and Silicon, and the Related Elements, vol. 187, no. 5, pp. 660-667, 2012.

[27] I. Kraicheva, E. Vodenicharova, B. Shivachev et al., "Anthracene-derived bis-aminophosphonates: crystal structure, in vitro antitumor activity and genotoxicity in vivo," Phosphorus, Sulfur, and Silicon and the Related Elements, vol. 188, no. 11, pp. 1535-1547, 2013.

[28] I. Kraicheva, I. Tsacheva, R. Nikolova, M. Topashka-Ancheva, I. Stoineva, and B. Shivachev, "Microwave assisted synthesis and X-ray structure of a novel anthracene-derived aminophosphonate. Enantioseparation of two $\alpha$-aminophosphonates and genotoxicity in vivo," Phosphorus, Sulfur, and Silicon and the Related Elements, vol. 192, no. 4, pp. 403-409, 2017.

[29] T. Prot, "Photoconductivity and electronic absorption spectra of Schiff bases, derivatives of 1-naphthoic and of 9-anthroic aldehydes," Roczniki Chemii, vol. 45, pp. 247-256, 1971.

[30] R. Tsevi, G. Todorova, K. Kossev et al., "Immobilization of bioactive substances on poly(alkylene phosphate)s, 1. Immobilization of 2-phenylethylamine," Macromolecular Chemistry, vol. 194, no. 12, pp. 3261-3269, 1993.

[31] K. Kossev, A. Vassilev, Y. Popova, I. Ivanov, and K. Troev, "Functionalization of poly(oxyethylene phosphonate) under phase-transfer catalyst conditions," Polymer, vol. 44, no. 7 , pp. 1987-1993, 2003. 


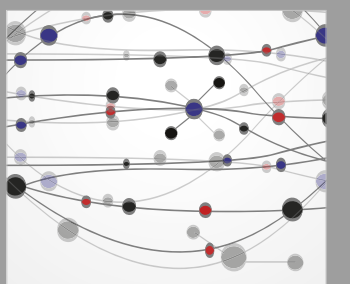

The Scientific World Journal
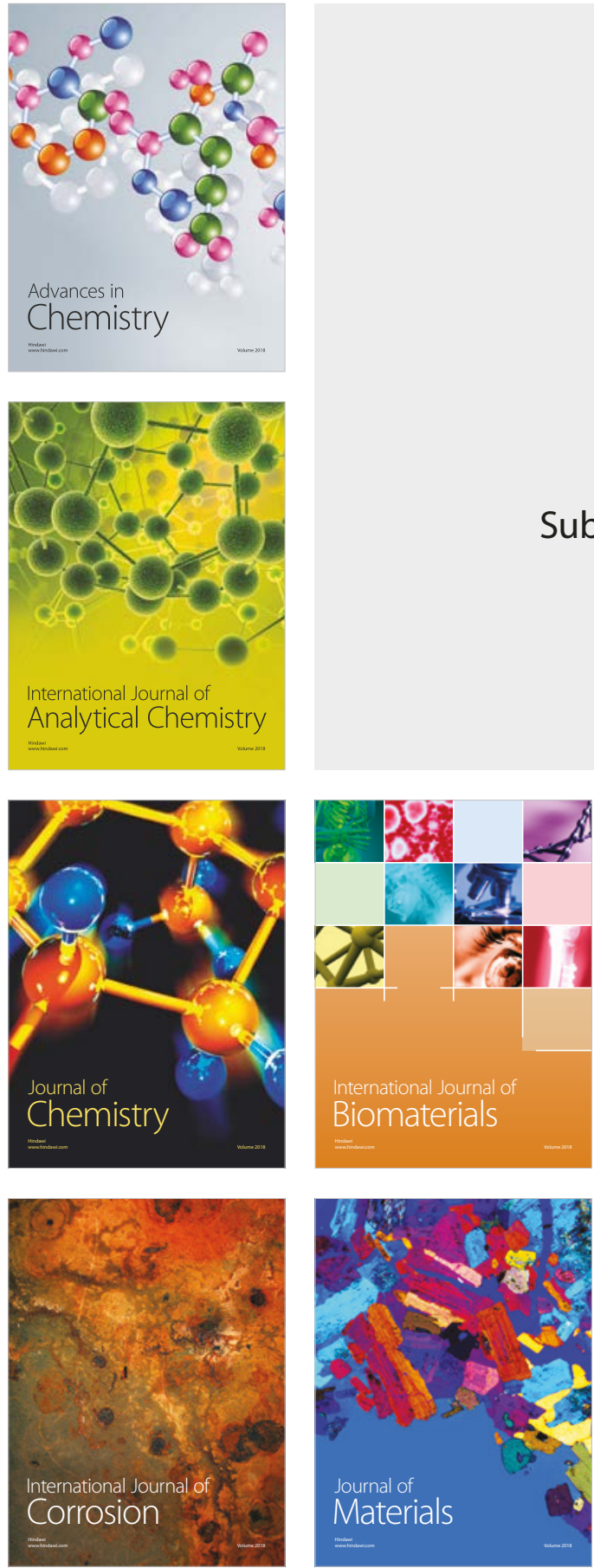

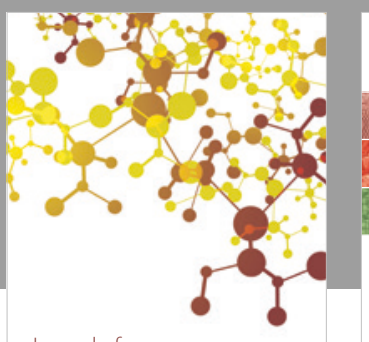

Journal of

Applied Chemistry
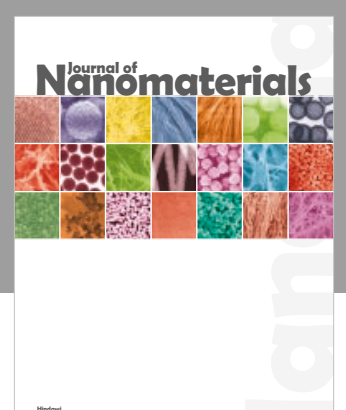

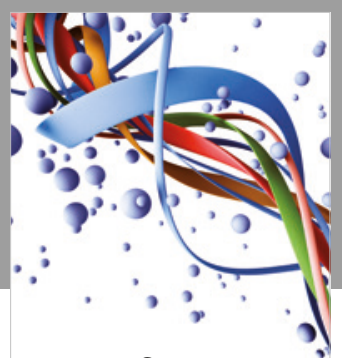

Scientifica

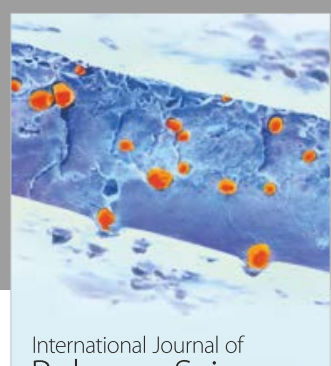

Polymer Science

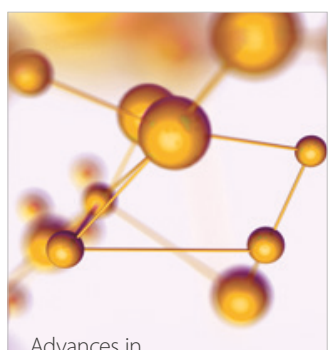

Physical Chemistry
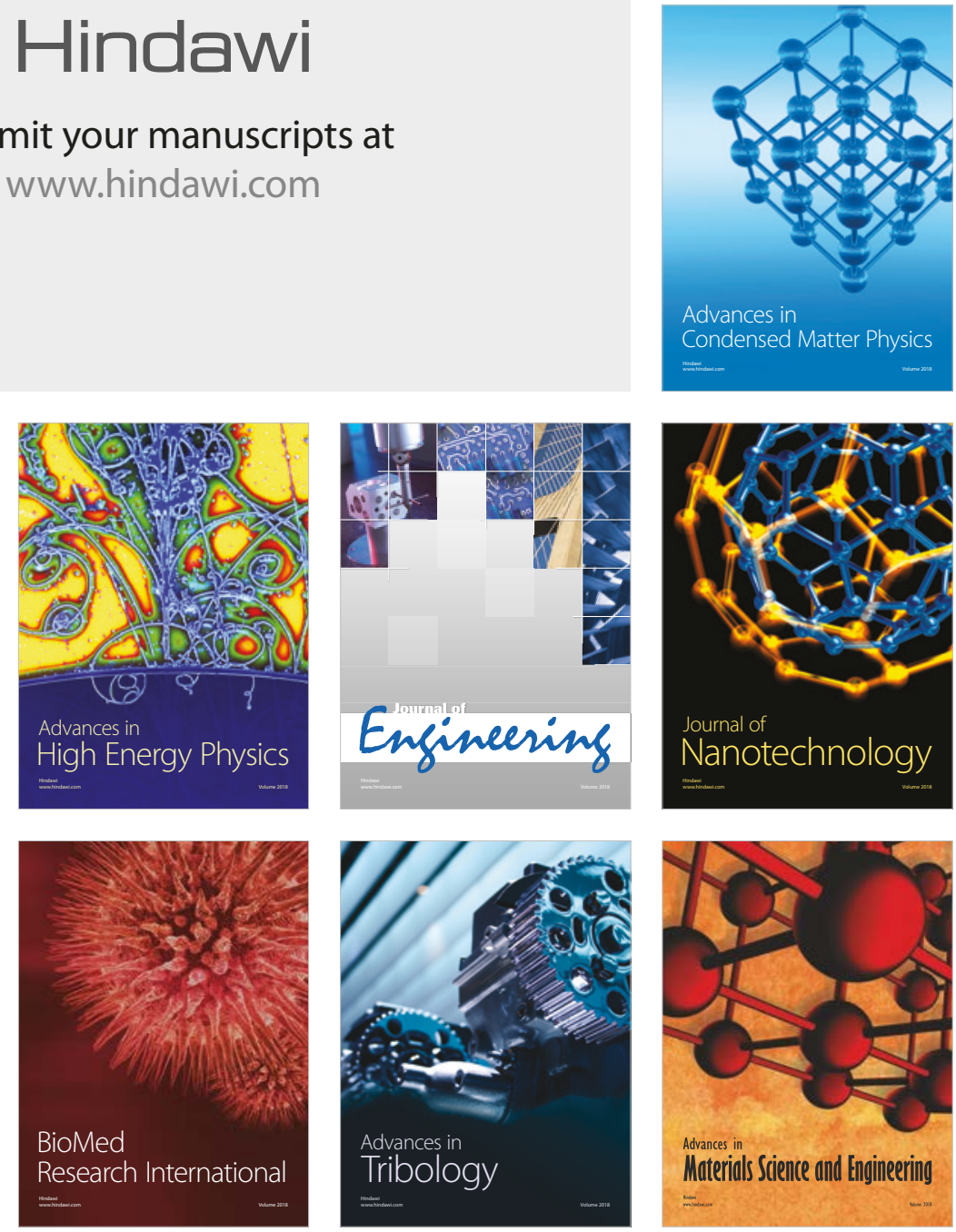